Bài báo khoa học

\title{
Xây dựng bản đồ ngập lụt phục vụ công tác chống ngập, quy hoạch đô thị trên bàn thành phố Hồ Chí Minh
}

\author{
Nguyễn Việt Hưng ${ }^{1}$, Nguyễn Quốc Cường², Bùi Việt Hưng ${ }^{3 *}$, Đặng Quang Thanh ${ }^{4}$ \\ ${ }^{1}$ Trung tâm Quản lý Hạ tầng kỹ thuật thành phố Hồ Chí Minh; \\ nguyenviethungtv@gmail.com \\ ${ }^{2}$ Sở Thông tin truyền thông thành phố Hồ Chí Minh; cuonglequoc@gmail.com \\ ${ }^{3}$ Trường Đại Học Khoa học Tự nhiện thành phố Hồ Chí Minh; buiviethung@gmail.com \\ ${ }^{4}$ Công ty TNHH DHI Việt Nam; tqd@dhigroup.com \\ *Tác giả liên hệ: nguyenviethungtv@gmail.com; Tel: +84-918445566.
}

Ban Biên tập nhận bài: 10/3/2021; Ngày phản biện xong: 12/4/2021; Ngày đăng bài: $25 / 5 / 2021$

Tóm tắt: Bài báo này trình bày kết quả nghiên cứu xác định giá trị thiệt hại do ngập lụt cho khu vực đô thị TP.HCM. Trong nghiên cứu này, các tác giả sử dụng số liệu điều tra khảo sát về ngập lụt và thiệt hại do ngập lụt tại toàn bộ các điểm thường xuyên ngập lụt trên địa bàn đô thị thành phố; sử dụng công cụ mô hình toán MIKE 11 và MIKE FLOOD để mô phỏng nguy cơ ngập lụt, sau đó kết hợp với công nghệ bản đồ (ArcGIS) xác định giá trị thiệt hại do ngập tương ứng. Trong đó, mức độ thiệt hại được phân chia theo hộ dân, hộ kinh doanh và đơn vị sản xuất theo đơn vị hành chính của thành phố. Giá trị thiệt hại của từng vùng nghiên cứu tương ứng với độ sâu ngập khác nhau đã được chỉ ra trong nghiên cứu này. Các giá trị thiệt hại này sẽ được ứng dụng trong quản lý rủi ro do ngập lụt đồng thời được dùng để xác định qui mô hợp lý và tiêu chuẩn an toàn cho công trình chống ngập của từng vùng nghiên cứu theo phương pháp phân tích rủi ro.

Từ khóa: Ngập lụt; Bản đồ ngập lụt; Bản đồ thiệt hại nhập lụt.

\section{Mở đầu}

Ngập lụt và thiệt hại do ngập lụt gây ra trên thế giới ngày càng trở lên nghiêm trọng, nó xảy ra nhiều nơi trên thế giới, và mức độ ảnh hưởng của ngập lụt tới cư dân đô thị là rất lớn. Trước thức trạng này, các quan chức Liên hiệp quốc khuyến cáo các quốc gia, tổ chức và cá nhân thay đổi hành vi ứng xử để có thể giảm thiểu tác động của các vụ thiên tai. Kêu gọi các chính phủ đầu tư vào những hệ thống phòng, chống lũ lụt và tưới tiêu; tránh xây dựng tại những khu vực có nguy cơ lũ lụt cao; giảm bớt các khu định cư ở vùng duyên hải; áp dụng các biện pháp bảo vệ nguồn cung cấp nước sạch và điện.

Trên thế giới, các nghiên cứu về đánh giá tác động ngập lụt đô thị rất nhiều và đa dạng tùy thuộc vào mức độ phát triển cũng như quy mô của các khu vực nghiên cứu-đô thị. Có thể liệt kê một số nghiên cứu về thiệt hại kinh tế do ngập lụt gây ra trong đô thị của một số nước sau:

Ở Đức đánh giá thiệt hại được thực hiện sau khi phỏng vấn và khảo sát sau trận lụt, kết hợp với các dữ liệu bảo hiểm và các đơn xin bồi thường thiệt hại kinh tế. Dữ liệu này có sẵn trong hệ thống cơ sở dữ liệu gọi lại HOWAS [1]. Cơ sở dữ liệu này là yếu tố chính trong việc phát triển các mô hình thiệt hại ICPR, MURL và Thủy lực. Các mô hình thiệt hại này chỉ được thực hiện cho các tòa nhà. Các đường cong độ sâu thiệt hại ở các mô hình khác nhau được sử dụng ở Đức [2]. 
Ở Anh, MCM là các hướng dẫn cơ bản để để đánh giá thiệt hại do ngập lụt. Hướng dẫn sử dụng cung cấp các đường cong thiệt hại tuyệt đối cho phép định lượng nhiều loại thiệt hại thành tiền [3]. Mô hình MCM dựa trên dữ liệu tổng hợp được tạo ra bằng cách khảo sát bằng bảng hỏi và kiến thức chuyên môn của các chuyên gia [3].

Ở Cộng hòa Séc, trong nghiên cứu các tiếp cận toán học cho đánh giá thiệt hại ngập dựa trên cơ sở sử dụng đất trong đô thị với trường hợp nghiên cứu là thành phố Prague năm 2006, đã thiết lập công thức tính tính thiệt hại kinh tế chung do ngập đô thị gây ra [4]. Thiệt hại do ngập lụt phụ thuộc vào loại hình sử dụng đất: Lũ lụt tạo ra hậu quả thiệt hại nhiều ở các khu vực đô thị hơn ở khu vực nông thôn. Cách phân loại đất sử dụng được đưa vào tính toán thiệt hại do lũ lụt, tương ứng với cách phân loại đất sử dụng theo chú giải MOLAND, giống với cơ sở dữ liệu của Châu Âu nhưng với mức độ sử dụng đất chi tiết hơn.

Bên cạnh những nghiên cứu trên, ta còn thấy rất nhiều những công trình nghiên cứu khác liên quan như: [5] đã sử dụng hình thức dạng cấu trúc và phi cấu trúc được lựa chọn với tính tới nhiều đối tượng khác nhau trong cộng đồng. Chuẩn hóa đánh giá thiệt hại của người dân theo lớp bảo hiểm, mỗi lớp có thiệt hại riêng dựa trên đường cong theo kích thước, loại công trình và tàn sản [6-7] đã đánh giá thiệt hại lũ lụt thông qua một số chỉ số về GDP của khu vực, giá trị thị trường bất động sản. [6] lập bản đồ che phủ đất để hỗ trợ nguy cơ lũ lụt và đánh giá thiệt hại do lũ lụt. [8] xây dựng bộ hướng dẫn và phương thức đánh giá thiệt hại lũ lụt cho Malaysia. [9] nghiên cứu thiệt hại do ngập lụt đô thị diễn biến theo mô phỏng mô hình và phân tích rủi ro lũ lụt và đánh giá rủi ro lũ lụt.

Tại Việt Nam nói chung và đối với Thành phố Hồ Chí Minh nói riêng, việc nghiên cứu phương pháp đánh giá thiệt hại cũng như xác định mức độ thiệt hại kinh tế do ngập lụt đô thị của người dân đã được quan tâm và thực hiện, nhưng vẫn ở mức rất hạn chế và còn khá nhiều vấn đề, lĩnh vực, thành phần thiệt hại kinh tế chưa được nghiên cứu. [10] thực hiện nghiên cứu đánh giá rủi ro và xác định giá trị thiệt hại do ngập lụt cho khu vực TP.HCM, áp dụng cho dự án chống ngập úng khu vực TP.HCM giai đoạn 1 . Theo nghiên cứu [11] về khả năng phục hồi của đô thị sau ngập lụt, trong đó nhấn mạnh yếu tố quy hoạch đô thị hợp lý cho việc giảm ngập và thiệt hại do ngập gây ra. Nghiên cứu cũng đã so sánh và làm rõ sự khác nhau giữa đô thị có thể "đàn hồi” hay "chống chọi”. Trong nghiên cứu, tác giả chỉ ra khả năng tự phục hồi, qua mức độ phục hồi đó, xác định mức độ thiệt hại kinh tế do ngập lụt đô thị cho khu vực đó. Trong nghiên cứu [12], đã nghiên cứu hệ thống quy trình tính thiệt hại tiềm năng do ngập, nghiên cứu về định lượng các thiệt hại hữu hình-thiệt hại do ngập gây ra tại các khu vực của Thành phố Hồ Chí Minh. Tuy nhiên, nghiên cứu chỉ "nhấn mạnh" tầm quan trọng của việc định lượng thiệt hại tiềm năng do ngập gây ra trong các nghiên cứu về rủi ro ngập. Theo nghiên cứu [13] nghiên cứu về cơ sở phương pháp luận của việc ước lượng giá trị kinh tế của phòng lũ trong điều kiện kinh tế thị trường cũng như trong điều kiện phát triển bền vững của kinh tế tài nguyên môi trường. Theo nghiên cứu [14] nghiên cứu về cơ sở phương pháp luận của việc ước lượng giá trị thiệt hại của biến đổi khí hậu phục vụ qui hoạch sử dụng đất, giao thông, tài nguyên nước và hạ tầng cơ sở cho TP. HCM" đánh giá một cách chi tiết và khoa học ảnh hưởng của $\mathrm{BĐKH}$ ở các địa phương và cho các lĩnh vực cụ thể và cho thấy những tác động đến Cần Giờ.

Thành phố Hồ Chí Minh hiện nay được xem là một đô thị có tiềm năng phát triển kinh tế trong khu vực và được tiên lượng sẽ ngày càng thu hút đầu tư trong và ngoài nước. Quá trình đầu tư phát triển sẽ đặt ra nhu cầu sau: cho những bước điều chỉnh quy hoạch, tổ chức lại không gian đô thị phù với nhu cầu cầu mở rộng không gian; xây dựng hệ thống quản lý tính hiệu quả của việc khai thác không gian đô thị tại các khu trung tâm hiện hữu nhằm hạn chế sự mở rộng của đô thị trên các khu vực không thuận lợi, đồng thời kiểm soát chặt chẽ sự phát triển của các khu vực mới (nhất là các khu công nghiệp, khu dân cư). Việc làm này cần phải dựa trên các tính toán với nguồn số liệu tin cậy về nhiều lĩnh vực khác nhau, đặc biệt là dữ liệu về hiện trang ngập lụt và những thiệt hại do ngập lụt gây ra; dữ liệu dựa trên phân 
tích tính toán trên bản đồ ngập lụt và bản đồ thiệt hại do ngập lụt gây ra, nhằm giảm thiểu những rủi ro thiệt hại và phát triển bền vững.

Do đó, đề xuất nhiệm vụ nghiên cứu " Điều tra khảo sát và đánh giá thiệt hại do ngập lụt đến kinh tế-xã hội; xây dựng bản đồ thiệt hại do ngập lụt phục vụ công tác chống ngập, quy hoạch đô thị trên địa bàn Thành phố Hồ Chí Minh" được đề xuất thực hiện để đánh giá những tác động và thiệt hại, rủi ro ngập ảnh hưởng đến kinh tế, con người và môi trường của người dân trong khu vực đô thị thành phố. Nghiên cứu này sẽ giúp chúng ta có cái nhìn chi tiết và rõ ràng về hiện trạng ngập và những ảnh hưởng, thiệt hại do ngập lụt gây ra, là cơ sở để đề xuất những giải pháp giảm ngập, những yêu cầu cần giải quyết để phục vụ phát triển kinh tếxã hội gắn liền với bảo vệ môi trường và phát triển bền vững. Bên cạnh đó,việc thực hiện nghiên cứu này là cơ sở nghiên cứu để các nhà quản lý đưa ra các biện pháp quản lý phù hợp với tình hình ngập lụt hiện nay, góp phần đánh giá chức năng của các công trình chống ngập đã và đang được thực hiện trên địa bàn Thành phố Hồ Chí Minh. Mục tiêu tổng quát của nghiên cứu này là: Điều tra khảo sát và đánh giá thiệt hại do ngập lụt đến kinh tế-xã hội trên địa bàn thành phố Hồ Chí Minh làm cơ sở cho việc xây dựng các loại bản đồ ngập và bản đồ thiệt hại kinh tế do ngập lụt gây ra phục vụ cho công tác điều hành chống ngập cũng như phục vụ công tác quy hoạch đô thị và phát triển bền vững của Thành phố.

\section{Phương pháp nghiên cứu}

\subsection{Giới thiệu khu vục nghiên cúu}

Phạm vi vùng nghiên cứu bao gồm khu vực đô thị bị ảnh hưởng thường xuyên của ngập lụt, cụ thể là 22 quận huyện trên tổng số 24 quận huyện gồm: Quận $1 ; 3 ; 4 ; 5 ; 6 ; 8 ; 10 ; 11$; Phú Nhuận; Bình Thạnh; Gò Vấp; Tân Bình; Tân Phú, 2; 7; 9; 12; Thủ Đức, Bình Tân, huyện Hóc Môn; Bình Chánh; Nhà Bè. Hai huyện không nằm trong phạm vi nghiên cứu là huyện Cần Giờ và Củ Chi (Hình 1$)$.

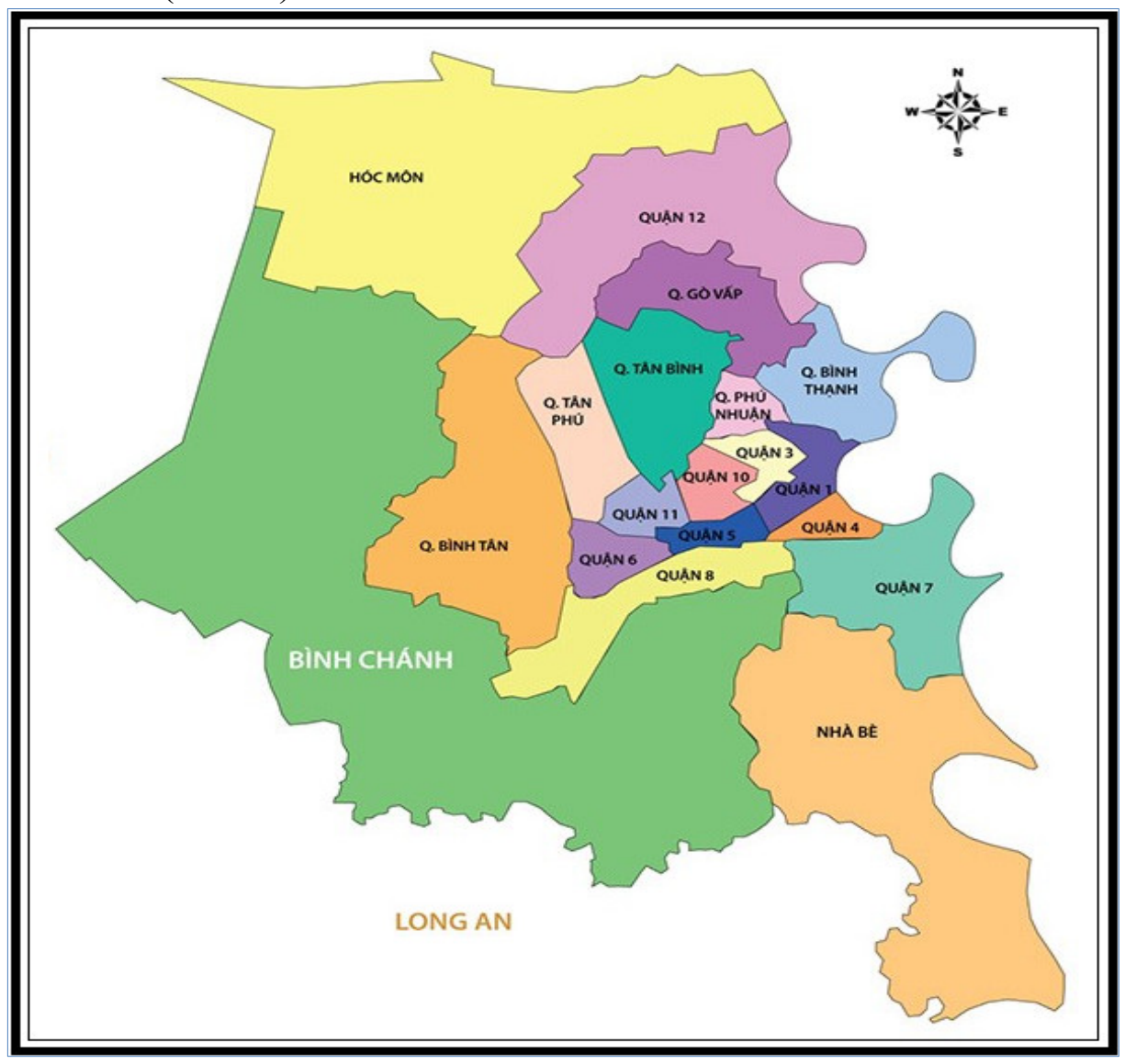

Hình 1. Các quận huyện Thành phố Hồ Chí Minh thuộc vùng nghiên cứu. 


\subsection{Phuơng pháp thiết lập hàm thiệt hại}

Đã có rất nhiều nghiên cứu liên quan tới thiệt hại do thiên tai gây ra cho sản xuất và đời sống người dân, vấn đề xác định dạng thiệt hại khá đa dạng và luôn mở rộng phạm vi theo lĩnh vực đánh giá thiệt hại. Các nội dung nghiên cứu của đề tài liên quan tới tác động cùng các loại hình tác động của ngập lụt đến các đối tượng như hộ dân và doanh nghiệp vừa và nhỏ trên địa bàn thành phố, các tác động của ngập lụt đến hoạt động sản xuất, kinh doanh và cuộc sống hàng ngày của người dân đã được xác định theo một số hình thức chính, các loại hình thiệt hại do ngập sẽ được đánh giá trong đề tài đã được xác định và thống kê cụ thể cho các đối tượng gồm hộ dân (hộ gia đình, hộ buôn bán) và doanh nghiệp vừa và nhỏ. Các loại hình thiệt hại do ngập gây ra được thống kê tại bảng 1.

Bảng 1. Tổng hợp những loại hình thiệt hại do ngập lụt.

\begin{tabular}{|c|c|c|}
\hline Loại & Thiệt hại trụ̣c tiếp & Thiệt hại gián tiếp \\
\hline $\begin{array}{l}\text { Hữu } \\
\text { hình }\end{array}$ & $\begin{array}{l}\text { - } \text { Thiệt hại về mặt cấu trúc nhà/sân/vườn.. } \\
\text { - Thiệt hại tài sản, hàng hóa... } \\
\text { - } \text { Phương tiện giao thông } \\
\text { - } \text { Chi phí kê kích và dọn dẹp... }\end{array}$ & $\begin{array}{l}\text { - Ùn tắt giao thông } \\
\text { - Gián đoạn kinh doanh } \\
\text { - Giảm thu nhập người lao động... } \\
\text { - Nghỉ việc hay đến nơi làm việc muộn..... }\end{array}$ \\
\hline $\begin{array}{l}\text { Vô } \\
\text { hình }\end{array}$ & $\begin{array}{l}\text { - Bệnh liên quan tới nước như cảm cúm, bệnh } \\
\text { ngoài da.. } \\
\text { - Dịich bệnh, bệnh truyền nhiễm.. } \\
\text { - Tồn hại khu vực văn hóa hoặc di sản } \\
\text { - Tổn hại sinh thái } \\
\text { - Sự bất tiện cho con người trong sinh hoạt và } \\
\text { kinh doanh, sản xuât... }\end{array}$ & $\begin{array}{l}\text { - Căng thẳng và lo lắng } \\
\text { - Phá vớ cuộc sống hàng ngày } \\
\text { - Mất cơ hội tăng thu nhập/doanh thu... } \\
\text { - Giảm giá trị đất } \\
\text { - } \quad \text { Suy yếu niềm tin vào cơ quan công quyền.... }\end{array}$ \\
\hline
\end{tabular}

Tính toán tổng thiệt hại do ngập lụt gây ra: Từ phân tích các loại hình thiệt hại do ngập khác nhau, cách xác định mức độ thiệt hại do ngập lụt đô thị trên cơ sở phân tích các dạng thiệt hại do ngập lụt đô thị gây ra cho từng đối tượng, mức độ thiệt hại được xác định cụ thể như sau:

Giá trị thiệt hại sau 1 lần ngập lụt = Giá trị thiệt hại trực tiếp sau 1 lần ngập + Giá trị thiệt hại gián tiếp sau 1 lần ngập

Giá trị thiệt hại trực tiếp = Tổng các chi phí để sửa chữa nhà cửa, đồ đạc, phương tiện, máy móc, dụng cụ,... sau 1 lần ngập (đơn vị: VNĐ) của từng đối tượng.

Giá trị thiệt hại gián tiếp $=$ Chi phí cho dọn dẹp và sắp xếp lại đồ đạc + Tiền khám chữa bệnh sau 1 lần ngập + Thu nhập của người lao động bị mât do nghỉ làm, kẹt xe, trễ giờ sau 1 lần ngập $=$ (Thời gian nghỉ làm + thời gian dọn dẹp + thời gian kẹt $x \mathrm{e}+$ thời gian trễ giờ $) \mathrm{x}$ 1 giờ tiền công lao động (đơn vị: VNĐ).

Để thiết lập hàm thiệt hại trong nghiên cứu này, nhóm nghiên cứu sẽ sử dụng cả hai phương pháp xây dựng hàm thiệt hại: phương pháp thứ nhất là điều tra khảo sát sau đó thống kê các giá trị thiệt hại; phương pháp thứ hai là sử dụng các công cụ để mô phỏng ngập lụt, sau đó dựa vào quan hệ giữa giá trị sử dụng đất và mức độ ngập lụt để xác định giá trị thiệt hại đó. Cách xác định thiệt hại theo phương pháp thứ hai cho phép sử dụng được những tiến bộ về hệ thống thông tin địa lý, đồng thời vẫn có thể tận dụng được một số kết quả điều tra hiện có. Quá trình xây dựng hàm thiệt hại được tiến hành theo các bước như sau: Phân loại thiệt hại; Xác định giá trị thiệt hại lớn nhất bằng phương pháp điều tra xã hội, định giá và thống kê; Xác định đường cong thiệt hại, còn gọi là hàm thiệt hại bằng cách điều tra xã hội, phân tích cơ chế vật lý hoặc sinh lý, thí nghiệm... cho mỗi loại thiệt hại.

Dạng phương trình thiệt hại được lựa chọn: Công thức tính toán thiệt hại bao gồm các loại hình thiệt hại hữu hình/vô hình do ngập lụt với hai yếu tố chính liên quan tới ngập là độ sâu cùng thời gian diễn ra ngập có thể gây thiệt hại.

Công thức thiệt hại dạng 1 :

$$
\mathrm{D}=\mathrm{A} 0+\mathrm{Ah} \mathrm{H}+\mathrm{AT} \mathrm{T}
$$


Trong đó $\mathrm{D}$ là thiệt hại cho một hộ gia đình trong 1 lần ngập (VNĐ); $\mathrm{H}$ là chiều sâu ngập trung bình $(\mathrm{cm})$; $\mathrm{T}$ là thời gian ngập trung bình (phút).

$\mathrm{A} 0, \mathrm{Ah}, \mathrm{AT}$ là các thông số được xác định cho từng loại đối tượng chịu tác động của ngâp lụt khác nhau và ứng với mức ngập gây thiệt hại khác nhau. Như vậy, bộ các thông số trên sẽ thay đổi theo mức độ sâu ngập và thời gian tác động khác nhau .với đơn vị lần lượt $\mathrm{a} 0$ (VNĐ), a1 (VNĐ/ chiều sâu-cm) và a2 (VNĐ/ thời gian-phút).

Với công thức thiệt hại dạng (1), khi xác định được mức độ ngập trung bình gồm các yếu tố chiều sâu gây thiệt hại, thời gian ngập (tính bằng $1 / 2$ thời gian nước rút hoàn toàn) cùng với thống kê số hộ nằm trong phạm vi ngập, chúng ta có thể ước lượng được mức độ thiệt hại kinh tế do lần ngập đó cho khu vực. Như vậy, công thức thiệt hại dạng (1) khá phù hợp với công tác quản lý thiên tai trong khu vực đô thị cũng như mức độ giản đơn để các cấp quản lý có thể thu thập, thống kê qua đó nhanh chóng xác định được mức độ thiệt hại.

Công thức thiệt hại dạng (2):

$$
\mathrm{D}=\mathrm{Box} \ln (\mathrm{Hq} \mathrm{d})+\mathrm{B}
$$

Trong đó $\mathrm{D}$ là tổng thiệt hại trong vùng nghiên cứu ứng với 1 lần ngập (VNĐ), Bo, $\mathrm{B}$ là các thông số ngập phụ thuộc vào mức ngập quy đổi khác nhau, Hqđ là chiều sâu ngập quy đổi được tính từ chiều sâu ngập thực $(\mathrm{h} \mathrm{cm})$ và thời gian ngập thực (T phút) và không có đơn vị.

Như vậy, bên cạnh việc xác định hàm thiệt hại với chiều sâu và thời gian thực, nghiên cứu cũng xác định mối quan hệ giữa thời gian ngập và mức độ ngập thông qua kết quả khảo sát $\mathrm{T}=\mathrm{ft}(\mathrm{h})$ từ đó $\mathrm{Hq}$ đ $=\mathrm{f}(\mathrm{h}, \mathrm{ft}(\mathrm{h}))$.

Thiết lập hàm thiệt hại do ngập: Từ kết quả khảo sát thiệt hại ngập lụt của hộ dân năm 2016-2018, tiến hành lọc các chỉ tiêu/ loại hình thiệt hại liên quan tới hàng hóa, ngưng kinh doanh,... ta sẽ có bảng tổng hợp thiệt hại cho hộ gia đình, doanh nghiệp. Tiếp theo, thiết lập hàm hồi quy (hàm thiệt hại) giữa thiệt hại với các yếu tố ngập là chiều sâu và thời gian cho 1 lần ngập cho 1 đối tượng, sau đó tiến hành phân tích hồi qui nhằm thiết lập hàm thiệt hại ngập. Đồng thời thiệt lập hàm quan hệ giữa chiều sâu ngập và thời gian ngập làm cơ sở cho hàm thiệt hại dạng 2. Kết quả khảo sát thiệt hại ngập lụt của hộ gia đình năm 2019 được sử dụng để điều chỉnh lại hàm thiệt hại dạng 1 và thiết lập hàm thiệt hại dạng 2.

\subsection{Phuơng pháp thiết lập bản đồ ngập lụt tù̀ số liệu điều tra khảo sát}

Việc xây dựng bản đồ ngập có thể được thực hiện bằng nhiều phương pháp khác nhau, trong đó GIS là một trong những phương pháp thông dụng và được sử dụng trong nhiều nghiên cứu. Với phương pháp GIS cần phải có một số dữ liệu quan trọng cần phải có bao gồm:

i) Mô hình số độ cao khu vực: Mô hình số độ cao cung cấp cao độ địa hình trên toàn khu vực. Dữ liệu độ cao có thể ở dạng ô lưới vuông (grid) hay ở dạng đa giác (TIN, vector). Nguồn dữ liệu để xây dựng mô hình số độ cao có thể là từ bản đồ địa hình, từ các ảnh viê̂n thám như từ ảnh vệ tinh (SRTM, ASTER, SPOT), ảnh chụp từ máy bay (không ảnh, Lidar), hay từ số liệu cao độ được thu thập từ phương pháp dẫn truyền cao độ truyền thống hoặc hiện đại (ví dụ: DGPS-Differential Global Positioning system).

ii) Số liệu ngập trong khu vực, Số liệu ngập được thu thập và điều tra trong giai đoạn từ năm 2016-2018 và khảo sát năm 2019 đã được thu thập tại 21 quận, huyện trên địa bàn thành phố Hồ Chí Minh. Từ đó xác định vùng ngập bằng phương pháp nội suy không gian. Sau đó, kết hợp với các số liệu từ mô hình số độ cao để xây dựng bản đồ phân vùng ngập lụt.

\subsection{Phuoong pháp thiết lập bản đồ thiệt hại}

Để lập và hiển thị bản đồ phân bố ngập cũng như phân bố các số liệu thiệt hại khảo sát và tính toán, đề tài đã thực hiện xây dựng công cụ với ba chức năng chính sau:

- Nội suy, phân tích khách quan từ số liệu khảo sát và tính toán để chuyển về số liệu trên các nút lưới đều trong không gian. 
- Thực hiện các phép toán thể hiện bản đồ phân bố bằng đường đồng mức và bằng tô màu vùng cùng giá trị.

- Chồng lớp với các lớp bản đồ nền: giao thông, thủy hệ, nhà ở dân cư, hiển thị bản đồ phân vùng lên bản đồ nền GIS.

Lập bản đồ phân bố: Nội suy hay Phân tích khách quan là một quá trình biến đổi thông tin từ những vị trí thám sát được phân bố ngẫu nhiên trong không gian thành số liệu trên những nút lưới điều hòa trong không gian. Ngoài khả năng tái tạo, một sơ đồ phân tích khách quan còn thực hiện nội suy trơn, phát hiện và khử đi số liệu xấu, và thực hiện phân tích nội bộ kiên định.

Nghiên cứu lựa chọn phương pháp Kriging để tính toán nội suy lưới số liệu ngập lụt và thiệt hai do ngập lụt. Phương pháp nội suy Kriging tính toán gần đúng các giá trị chưa biết bằng công thức nội suy tuyến tính có trọng số của các giá trị thám sát:

$$
\hat{\mathrm{v}}=\sum_{\mathrm{j}=1}^{\mathrm{n}} \mathrm{w}_{\mathrm{j}} \mathrm{v}_{\mathrm{j}} ; \sum_{\mathrm{j}=1}^{\mathrm{n}} \mathrm{w}_{\mathrm{j}}=1
$$

Trong đó $\hat{\mathrm{v}}$ là giá trị chưa biết, cần tính toán; $\mathrm{Wj}$ là hàm trọng số; $\mathrm{v}_{\mathrm{j}}$ là giá trị tại các điểm thám sát.

Sai số $\mathrm{r}_{i}$ của hàm nội suy tuyến tính được xác định bằng sai số giữa tính toán và thám sát tại cùng một điểm:

Sai số trung bình được tính toán theo công thức (4):

Sai số trung bình được tính toán theo công thức (5):

$$
\tau_{\mathrm{i}}=\bar{v}-v_{\mathrm{i}}
$$

$$
\mathrm{m}_{\tau}=\frac{1}{\mathrm{k}} \sum_{\mathrm{i}=1}^{\mathrm{k}} \tau_{\mathrm{i}}=\frac{1}{\mathrm{k}} \sum_{\mathrm{i}=1}^{\mathrm{k}} \bar{v}_{\mathrm{i}}-v_{\mathrm{i}}
$$

Khi đó sai số khác biệt là:

$$
\delta_{\mathrm{R}}^{2}=\frac{1}{\mathrm{k}} \sum_{\mathrm{i}=1}^{\mathrm{k}}\left(\tau_{\mathrm{i}}-\mathrm{m}_{\mathrm{R}}\right)^{2}=\frac{1}{\mathrm{k}} \sum_{\mathrm{i}=1}^{\mathrm{k}}\left[\overline{\mathrm{v}}_{\mathrm{i}}-\mathrm{v}_{\mathrm{i}}-\frac{1}{\mathrm{k}} \sum_{\mathrm{i}=1}^{\mathrm{k}}\left(\overline{\mathrm{v}}_{\mathrm{i}}-\mathrm{v}_{\mathrm{i}}\right)\right]^{2}
$$

\section{Kết quả và thảo luận}

\subsection{Kết quả Thiết lập hàm thiệt hại do ngập}

Trên cơ sở kết quả thiệt hại trực tiếp và gián tiếp thu được từ số liệu điều tra khảo sát, hàm thiệt hại do ngập lụt tác động tới các đối tượng (hộ gia đình, hộ kinh doanh và doanh nghiệp) trên địa bàn các quận huyện của Thành phố có dạng như sau:

Hàm thiệt hại dạng 1: $\quad \mathrm{D}=\mathrm{Ao}+\mathrm{Ah} \mathrm{h}(\mathrm{cm})+\mathrm{At} \mathrm{T}$ (phút)

Hàm thiệt hại dạng 2: $\quad \mathrm{D}=\mathrm{Bo} \operatorname{Ln}(\mathrm{Hqd})+\mathrm{B}$ với $\mathrm{Hq}$ đ $=(\mathrm{h} \times(\mathrm{a} \operatorname{Ln}(\mathrm{h})+\mathrm{b}) 1 / 2$.

Bộ thông số $\mathrm{Ao}, \mathrm{Ah}$ và $\mathrm{At}$ thuộc hàm thiệt hại dạng (1) và $\mathrm{Bo}, \mathrm{B}$ thuộc hàm thiệt hại dạng (2) tương ứng cho từng quận huyện cho từng đối tượng được tổng hợp trong các Bảng 2. Từ bộ thông số trong bảng 1 , chúng ta sẽ xây dựng được đường cong thiệt hại có dạng tiêu

\begin{tabular}{|c|c|c|c|c|c|c|c|c|c|c|}
\hline \multicolumn{2}{|c|}{ Đối tượng: Gia Đình } & \multirow{2}{*}{\multicolumn{3}{|c|}{$\begin{array}{c}\text { Hàm thiệt hại với mức ngập } \\
\text { Theo } \mathrm{h}(\mathrm{cm}) \text { và } \mathrm{T}(\mathrm{phú}) \\
\end{array}$}} & \multirow{2}{*}{\multicolumn{2}{|c|}{\begin{tabular}{|l}
$15-30$ cm \\
Theo $\mathrm{H}_{\text {quy dổi }}$
\end{tabular}}} & \multirow{2}{*}{\multicolumn{2}{|c|}{$\begin{array}{c}30-45 \mathrm{~cm} \\
\text { Theo } \mathrm{H}_{\text {quy }} \text { đổi }\end{array}$}} & \multirow{2}{*}{\multicolumn{2}{|c|}{$\begin{array}{c}15-45 \mathrm{~cm} \\
\text { Theo } \mathrm{H}_{\text {quy đổi }}\end{array}$}} \\
\hline \multirow{2}{*}{ TT } & \multirow{2}{*}{$\begin{array}{c}\text { Tên } \\
\text { khu vực }\end{array}$} & & & & & & & & & \\
\hline & & Ao & $\mathrm{Ah}$ & At & Bo & $\mathrm{B}$ & Bo & $\mathrm{B}$ & Bo & B \\
\hline 1 & Quận 12 & $-1,192$ & 0,046 & 0,020 & 1,558 & $-4,586$ & 2,946 & $-9,645$ & 2,119 & $-6,416$ \\
\hline 2 & Quận Thu Đức & & 0,023 & 0,014 & 1,321 & $-3,709$ & 1,953 & $-6,120$ & 1,610 & $-4,739$ \\
\hline 3 & Quận B.Thạnh & $-1,743$ & 0,102 & 0,005 & 1,858 & $-5,341$ & 3,928 & $-12,988$ & 2,707 & $-8,181$ \\
\hline
\end{tabular}
biểu như hình 1 .

Bảng 2. Tổng hợp thông số của các hàm thiệt hại dạng (1) và (2) theo các mức ngập cho đối tượng Hộ gia đình. 


\begin{tabular}{|c|c|c|c|c|c|c|c|c|c|c|}
\hline \multicolumn{2}{|c|}{ Đối tượng: Gia Đình } & \multirow{2}{*}{\multicolumn{3}{|c|}{$\begin{array}{c}\text { Hàm thiệt hại với mức ngập } \\
\text { Theo } h(\mathrm{~cm}) \text { và } T(\text { phút) } \\
\end{array}$}} & \multirow{2}{*}{\multicolumn{2}{|c|}{\begin{tabular}{c|} 
15-30 cm \\
Theo $H_{\text {quy đổi }}$ \\
\end{tabular}}} & \multirow{2}{*}{\multicolumn{2}{|c|}{$\begin{array}{c}30-45 \text { cm } \\
\text { Theo } \mathrm{H}_{\text {quy đổi }} \\
\end{array}$}} & \multirow{2}{*}{\multicolumn{2}{|c|}{$\begin{array}{c}15-45 \mathrm{~cm} \\
\text { Theo } \mathrm{H}_{\text {quy dổi }}\end{array}$}} \\
\hline \multirow{2}{*}{ TT } & \multirow{2}{*}{$\begin{array}{c}\text { Tên } \\
\text { khu vực }\end{array}$} & & & & & & & & & \\
\hline & & Ao & $\mathrm{Ah}$ & At & Bo & $\mathrm{B}$ & Bo & $\mathrm{B}$ & Bo & $\mathrm{B}$ \\
\hline 4 & Quận 2 & $-0,490$ & 0,032 & 0,011 & 0,577 & $-1,206$ & 1,790 & $-5,515$ & 0,921 & $-2,160$ \\
\hline 5 & Quận 4 & & & & 1,201 & $-3,362$ & 1,876 & & 1,508 & $-4,403$ \\
\hline 6 & Quận 5 & & & & 402 & $-4,036$ & 2,534 & 87 & 1,881 & $-5,593$ \\
\hline 7 & Quận 9 & & & & 2,606 & $-7,8$ & 4,365 & -14, & 3,356 & -10 \\
\hline 8 & Quận 6 & & & & 1,349 & $-3,98$ & 2,561 & & 1,862 & \\
\hline 9 & Quận 7 & - & 0,06 & 009 & 1,390 & $-4,155$ & 2,873 & $-9,639$ & 1,987 & $-6,136$ \\
\hline 10 & Quận 8 & $-0,290$ & 0,023 & 0,016 & 1,126 & $-2,955$ & 1,903 & $-5,804$ & 1,456 & $-4,051$ \\
\hline 11 & Huyện Nhà Bè & $-0,375$ & 0,000 & 0,023 & 1,386 & $-4,160$ & 1,971 & $-6,363$ & 1,646 & $-5,054$ \\
\hline 12 & Quận Tân Phú & $-0,478$ & 0,034 & 0,014 & 1,392 & $-3,880$ & 2,181 & $-6,796$ & 1,752 & $-5,119$ \\
\hline 13 & Huyện H.Môn & $-0,514$ & 0,032 & 0,013 & 1,220 & $-3,399$ & 2,025 & $-6,365$ & 1,575 & $-4,602$ \\
\hline 14 & Quận B.Tân & $-1,075$ & 0,032 & 0,034 & 2,100 & $-6,176$ & 3,302 & $-10,552$ & 2,625 & $-7,922$ \\
\hline 15 & Quận 1\&3 & $-0,227$ & 0,033 & 0,010 & 0,878 & $-2,006$ & 1,770 & $-5,239$ & 1,231 & $-3,146$ \\
\hline 16 & Quận 11 & $-0,933$ & 0,051 & 0,021 & 1,711 & $-4,690$ & 3,139 & $-9,884$ & 2,303 & $-6,633$ \\
\hline 17 & Quận T.Binh & $-0,146$ & 0,010 & 0,022 & 1,151 & $-2,985$ & 1,764 & $-5,202$ & 1,418 & $-3,861$ \\
\hline 18 & Quận Gò Vấp & $-1,197$ & 0,033 & 0,037 & 2,334 & $-6,926$ & 3,488 & $-11,145$ & 2,852 & $-8,671$ \\
\hline 19 & Quận P.Nhuận & $-1,620$ & 0,078 & 0,022 & 2,422 & $-7,072$ & 4,311 & $-13,937$ & 3,230 & $-9,752$ \\
\hline 20 & H.B.Chánh & $-0,568$ & 0,029 & 0,020 & 1,392 & $-3,818$ & 2,370 & $-7,380$ & 1,806 & $-5,183$ \\
\hline
\end{tabular}

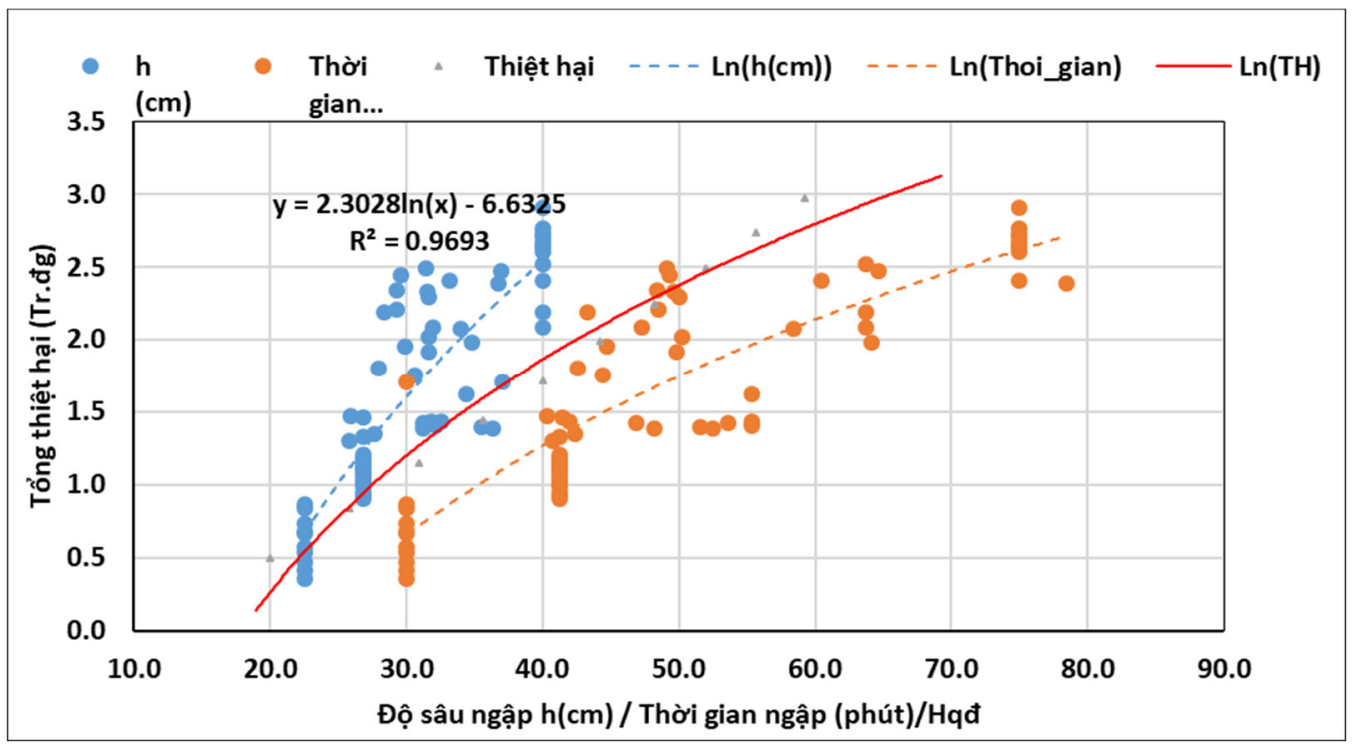

Hình 2. Đường thiệt hại ngập ứng với mức ngập $\mathrm{h}=15-45 \mathrm{~cm}$.

\subsection{Bản đồ thiệt hại do ngập lụt trên địa bàn TP.HCM}

Để hiện thị bản đồ phân bố ngập lụt và thiệt hại do ngập lụt trên bản đồ nền GIS, đề tài đã thực hiện thiết kế công cụ gồm các bước sau:

Thực hiện truy vấn thông tin bằng các công cụ như trình bày ở phần 2.

- Chọn cột thông tin cần hiển thị nội dung trên bản đồ;

- Công cụ sẽ tự dộng nội suy từ số liệu điều tra khảo sát vừa được truy vấn;

- Thực hiện phương pháp thể hiện phân bố bằng đường đồng mức;

- Thực hiện chồng lớp và hiển thị phân bố trên nền bản đồ GIS.

Nghiên cứu đã xử lý, tính toán, thiết lập được:

- 21 bản đồ thiệt hại do ngập của hộ dân cho 21 quận-huyện và 01 bản đồ thiệt hại cho toàn thành phố giai đoạn 2016-2018;

- 21 bản đồ thiệt hại do ngập của doanh nghiệp cho 21 quận-huyện và 01 bản đồ thiệt hại cho toàn thành phố giai đoạn 2016-2018; 
- 21 bản đồ thiệt hại do ngập của hộ dân cho 21 quận-huyện và 01 bản đồ thiệt hại cho toàn thành phố điều tra khảo sát năm 2019;

- 21 bản đồ thiệt hại do ngập của doanh nghiệp cho 21 quận-huyện và 01 bản đồ thiệt hại cho toàn thành phố điều tra khảo sát năm 2019.

Minh họa 02 bản đồ thiệt hại do ngập đối với hộ dân (hình 2) và doanh nghiệp (hình 3) trên địa bàn Quận 11 giai đoạn 2016-2018.

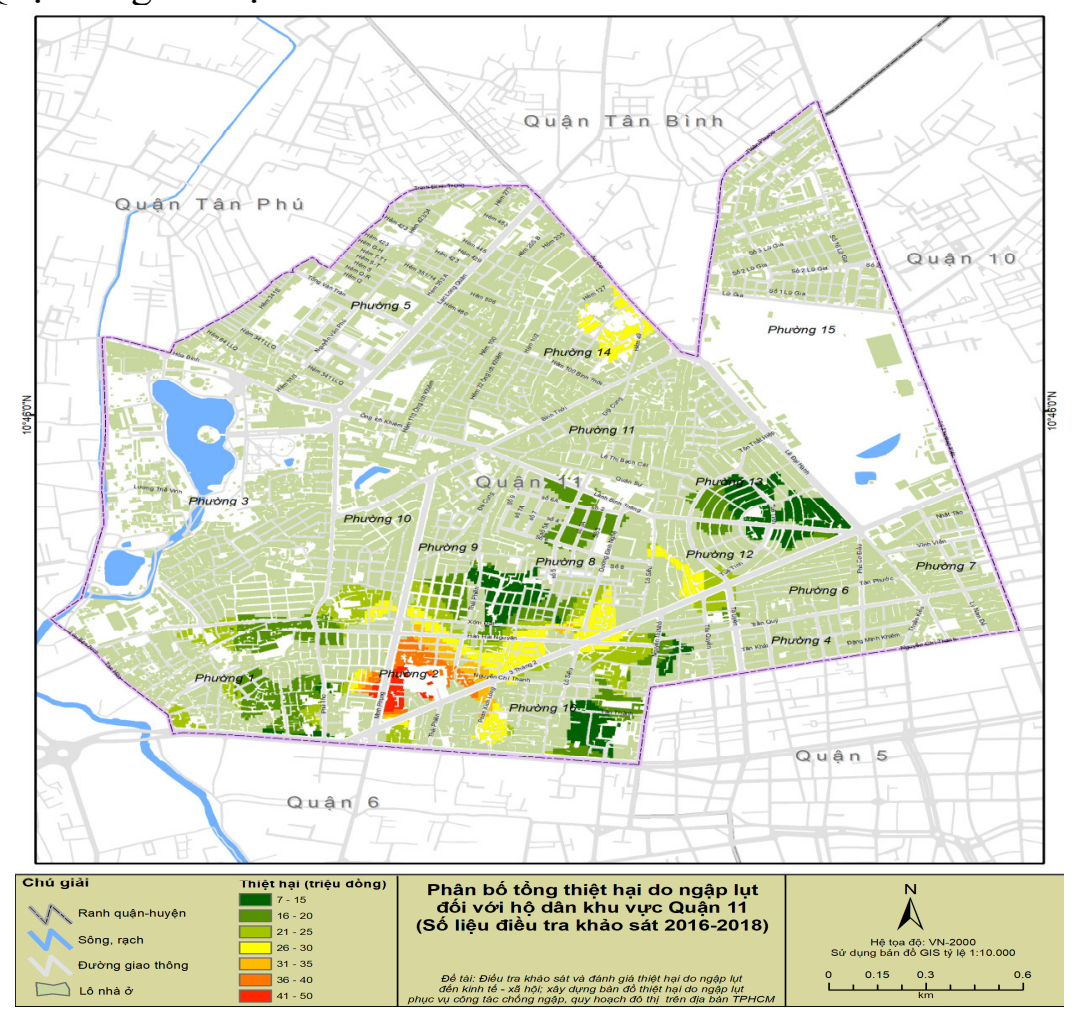

Hình 3. Bản đồ thiệt hại do ngập lụt của hộ dân trên địa bàn quận 11 (2016-2018).

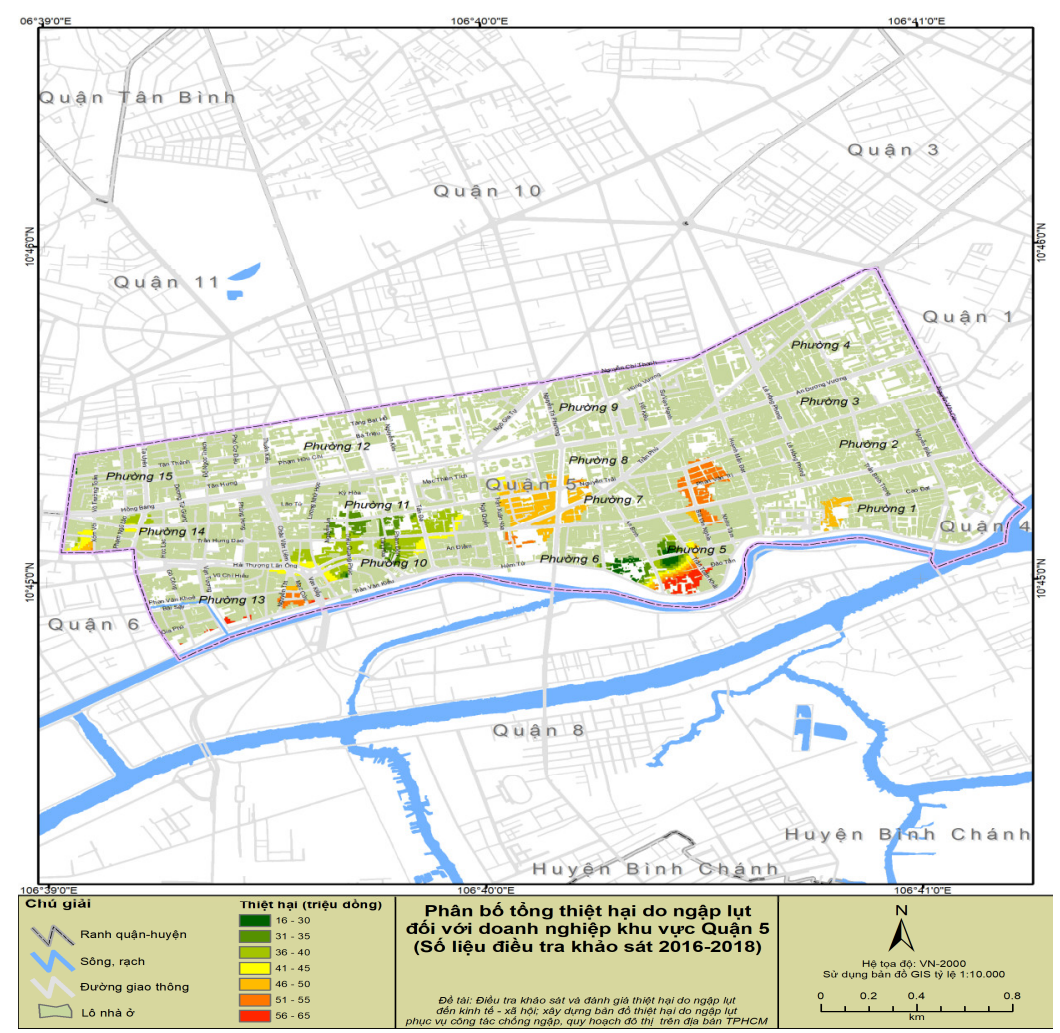

Hình 4. Bản đồ thiệt hại do ngập lụt của doanh nghiệp trên địa bàn quận 5 (2016-2018). 


\section{Kết luận}

Kết quả nghiên cứu làm cơ sở khoa học xác định các dạng thiệt hại kinh tế cụ thể và có "khả thi" tính toán do tác động bất lợi của ngập lụt trên địa bàn Thành phố cũng như thiết lập các công thức tính toán được các loại thiệt hại kinh tế đó; làm cơ sở cho xây dựng một phần bộ công cụ hỗ trợ ra quyết định cho cơ quan và nhà quản 1 .

Nghiên cứu bước đầu sẽ xác lập hệ thống thu thập số liệu thiệt hại cũng như mức độ ngập lụt trên địa bàn thành phố từ các đơn vị cấp phường xã, quận huyện, làm cơ sở tính toán đánh giá mức độ thiệt hại (tổng số, bình quân hay mức giao động) của người dân chịu tác động và thể hiện kết quả tính toán, đánh giá trên các công cụ quản lý (bản đồ, cơ sở dữ liệu, công cụ phân tích đánh giá) cho đơn vị quản lý liên quan.

Với kết quả thu được của nhiệm vụ nghiên cứu này, có thể khẳng định đây sẽ là các dữ liệu rất quan trọng trong công tác quy hoạch đô thị và phát triển các lĩnh vực kinh tế-xã hội và bảo vệ môi trường trên địa bàn Thành phố Hồ Chí Minh.

Úng dụng các phương pháp nghiên cứu về điều tra khảo sát, phương pháp phân tích thiết kế, phương pháp phân tích khách quan và phương pháp GIS, đề tài đã xây dựng được bộ bản đồ thiệt hại do ngập lụt cho 21 quận huyện trên địa bàn TPHCM.

Các bản đồ được lập dựa trên nền các lớp bản đồ GIS của khu vực TPHCM tỷ lệ 1:10,000 và thể hiện phân bố thiệt hại trên lớp nhà ở dân cư, Do vậy nhu cầu cập nhật số liệu về lớp nhà ở dân cư cần phải thường xuyên, căn cứ vào tốc độ xây dựng nhà ở, đô thị hóa của TP.HCM.

Đóng góp của tác giả: Xây dựng ý tưởng nghiên cứu: N.V.H., B.V.H.; Lựa chọn phương pháp nghiên cứu: N.V.H., B.V.H., Đ.Q.T.; Xử lý số liệu: N.V.H., N.Q.C.; Tính toán: N.V.H., B.V.H., Đ.Q.T.; Phân tích kết quả: N.V.H., B.V.H.; Viết bản thảo bài báo: N.V.H.; Chỉnh sửa bài báo: N.Q.C.

Lời cảm ơn: Nghiên cứu này được thực hiện dưới sự tài trợ của nhiệm vụ nghiên cứu khoa học và công nghệ cấp Thành phố: "Điều tra khảo sát và đánh giá thiệt hại do ngập lụt đến kinh tế-xã hội; xây dựng bản đồ thiệt hại do ngập lụt phục vụ công tác chống ngập, quy hoạch đô thị trên địa bàn Thành phố Hồ Chí Minh".

Lời cam đoan: Tập thể tác giả cam đoan bài báo này là công trình nghiên cứu của tập thể tác giả, chưa được công bố ở đâu, không được sao chép từ những nghiên cứu trước đây; không có sự tranh chấp lợi ích trong nhóm tác giả.

\section{Tài liệu tham khảo}

1. Merz, B.; Kreibich, H.; Schwarze, R.; Thieken, A. Assessment of economic flood damage. Nat. Hazards Earth Syst. Sci. 2010, 10, 1697-1724.

2. Olesen, L.; Löwe, R.; Arnbjerg-Nielsen, K. Flood damage assessment - Literature review and recommended procedure, Cooperative Research Centre for Water Sensitive Cities, 2017. ISBN 978-1-921912-39-9.

3. Penning-Rowsell, E.C. A "realist" approach to the extent of flood risk in England and Wales. In: Klijn F, Schweckendiek T (eds) Comprehensive flood risk management: research for policy and practice, Taylor and Francis, London, 2013.

4. Genovese, E. A methodological approach to land use-based flood damage assessment in urban areas: Prague case study. The mission of the Institute for Environment and Sustainability is to provide scientific and technical support to the European Union's policies for protecting the environment and the EU Strategy for Sustainable Development, 2006.

5. Price, R.K.; Vojinovic, Z. Urban flood disaster management. Urban Water J. 2008, 5, 259-276.

6. nunes Correia, F.; Fordham, M.; da GRAča Saraiva, M.; Bernardo, F. Flood Hazard Assessment and Management: Interface with the Public. Water Resour. Manage. 
1994, 12, 209-227.

7. van der Sande, C.J.; de Jong, S.M.; de Roo, A.P.J. A Segmentation and Classification Approach of IKONOS-2 Imagery for Land Cover Mapping to Assist Lood Risk and Food Damage Assessment. Int. J. Appl. Earth Obs. Geoinf. 2003, 4, 217-229.

8. Romali, N.S.; Sulaiman, M.A.K.; Yusop, Z.; Ismail, Z. Flood Damage Assessment: A Review of Flood Stage-Damage Function Curve, In: Abu Bakar S.; Tahir W.; Wahid M.; Mohd Nasir S.; Hassan R. (eds) ISFRAM 2014, Springer, Singapore, 2015, 147-159. https://doi.org/10.1007/978-981-287-365-1_13.

9. Morita, M. Flood Risk Impact Factor for Comparatively Evaluating the Main Causes that Contribute to Flood Risk in Urban Drainage Areas. Water 2014, 6, 253-270.

10. Bảo, L.X.; Công, M.V. Đánh giá rủi ro kinh tế do ngập lụt, ứng dụng cho Dự án chống ngập khu vực Thành phố Hồ Chí Minh giai đoạn 1. Tạp chí Khoa học kỹ thuật thủy lợi và môi trường 2016, 55, 55-72.

11. Duy, P.N. Khả năng hồi phục của Đô thị: Kinh nghiệm giảm thiểu rủi ro ngập lụt. Tạp chi Quy hoạch đô thị 2015, 22, 50-55.

12. Phi, H.L. Biến đổi khí hậu cục bộ và vấn đề ngập lụt đô thị ở Thành phố Hồ Chí Minh. Kỷ yếu Hội nghị Khoa học và Công nghệ lần thứ 11, ngày 21-23/10, 2009.

13. Khiêm, Đ.V.; Hòa, B.T.T. Cơ sở lý luận ước lượng giá trị kinh tế của phòng chống lũ. Tạp chí Khoa học Kĩ thuật Thủy lợi \& Môi trường 2010, 31, tr, 8.

14. Phùng, N.K.; Tâm, L.V. Nghiên cứu và đánh giá mô hình đánh giá tác động của biến đổi khí hậu đến các yếu tố tự nhiên, con người, kinh tế-xã hội Tp.HCM, 2011.

\title{
Building flood damage maps in service of the fight against flooding, urban planning in Ho Chi Minh City
}

\author{
Nguyen Viet Hung ${ }^{1}$, Nguyen Quoc Cuong ${ }^{2}$, Bui Viet Hung ${ }^{*}$, Dang Quang Thanh ${ }^{4}$ \\ ${ }^{1}$ Ho Chi Minh City Technical Infrastructure Management Center; \\ nguyenviethungtv@gmail.com \\ ${ }^{2}$ Department of Information and Communication of Ho Chi Minh City; \\ cuonglequoc@gmail.com \\ ${ }^{3}$ Ho Chi Minh City University of Natural Sciences; buiviethung@gmail.com \\ ${ }^{4}$ DHI Vietnam Company Limited; tqd@dhigroup.com
}

\begin{abstract}
This paper presents the results of the inundation damage determination study for the urban area of Ho Chi Minh City. In this study, the authors use survey data on inundation and damage due to inundation at all the frequently flooded sites in the city urban area; using mathematical modeling tools MIKE 11 and MIKE FLOOD to simulate flood risk, then combined with map technology (ArcGIS) to determine the value of damage due to flooding respectively. In which, the level of damage is divided by households, business households and production units according to the administrative unit of the city. The value of damage of each study area corresponding to different inundation depth was indicated in this study. These values of damage will be applied in flood risk management and also used to determine the reasonable scale and safety standards of the flood protection works of each study area according to the risk analysis method.
\end{abstract}

Keywords: Flood damage maps; Inundation damage; Flooding. 